\title{
INTERACTION OF THE FUNGICIDE TEBUCONAZOLE WITH HUMAN SERUM ALBUMIN: A PRELIMINARY STUDY
}

\author{
Staničová, J. ${ }^{1,3}$, Želonková, K. ${ }^{1}$, Verebová, V. ${ }^{1}$, Holečková, B. ${ }^{2}$, Dianovský, J. ${ }^{2}$ \\ ${ }^{1}$ Institute of Biophysics \\ ${ }^{2}$ Institute of Genetics \\ University of Veterinary Medicine and Pharmacy, Komenského 73, 04181 Košice \\ Slovakia \\ ${ }^{3}$ Institute of Biophysics and Informatics, First Faculty of Medicine, Charles University, Kateřinská 1, Praha \\ Czechia
}

jana.stanicova@uvlf.sk

\section{ABSTRACT}

The interactions between the fungicide tebuconazole and human serum albumin were investigated using fluorescence and circular dichroism spectroscopies. The experimental results showed that the fluorescence quenching of the protein by the tebuconazole molecule was a result of the formation of a ligand-protein complex with a binding constant of $8.51 \times 10^{3} 1 . \mathrm{mol}^{-1}$ and the number of binding sites in the macromolecule was close to 1 . These findings demonstrated the fact that although the binding affinity of tebuconazole to the protein may be slight, it was very similar to other triazole fungicides. In addition, tebuconazole stabilized the a-helical secondary structure of the human serum albumin due to the increase of the $a$-content in the protein macromolecule.

Key words: association constant; fluorescence spectroscopy; human serum albumin; interaction; tebuconazole

\section{INTRODUCTION}

Tebuconazole [1-(4-chlorophenyl)-4,4-dimethyl 3-(1,2,4triazol-1-ylmethyl) pentan-3-ol] (Fig. 1) is a representative of triazoles that are a class of fungicides largely used in agriculture as crop protection products [3]. Their antifungal activity is due to their ability to inhibit the P450 enzyme, which blocks the conversion of lanosterol to ergosterol causing disruption of the fungal cellular wall [5]. But the inhibition potency of these triazole fungicides including tebuconazole (TB) is not limited to fungi; they may also inhibit other P450-mediated activities resulting in various adverse effects [21].

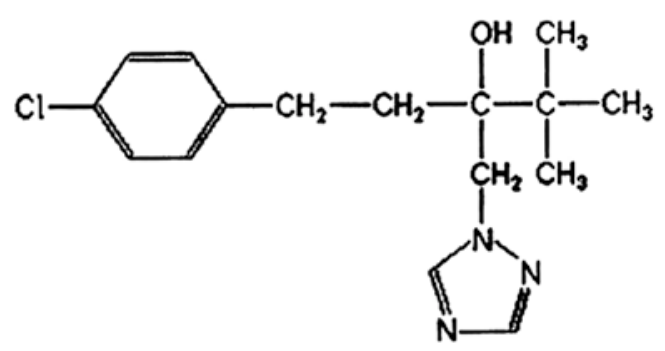

Fig. 1. The chemical structure of tebuconazole 
TB is the triazole fungicide, which is applied on a number of crops such as grapes, rice, fruits, and vegetables because of its broad-spectrum antifungal activity. This fungicide had been classified by the US EPA as Group C-Possible Human Carcinogen [27]. TB is persistent in soils and presents moderate mobility [6]. It is classified as toxic to aquatic organisms and may cause long-term adverse effects in the aquatic environment [2]. The presence of TB in stream water has increased in recent years [18] and its concentrations detected in surface waters were up to $175-200 \mu \mathrm{g} . \mathrm{l}^{-1}$ [7]. The results obtained by Liang et al. [17] indicated that exposure to TB could alter thyroid hormone levels as well as gene transcription in zebrafish larvae. Commercial formula Orius 25EW containing $25 \%$ of tebuconazole applied in agriculture as a leaf and ear spray pesticide has been studied by Holečková et al. [12]. In this study, significant chromosomal aberrations in lymphocytes induced by the fungicide were discovered. Furthermore, TB-based fungicide induces sister chromatid exchange in bovine peripheral lymphocytes [26]. What's more, TB was found in human beings with the maximal concentrations of $19.2 \mu \mathrm{g} . \mathrm{l}^{-1}$ and $2.22 \mathrm{ng} . \mathrm{kg}^{-1}$ in urine and hair samples, respectively, from farm workers $[9,22]$.

In fact, because so little is known about the long-term toxicity of TB and other triazoles to vertebrates at this time, it is not possible to ascertain whether these molecules present a risk for mammalians chronically exposed to low doses. As a consequence, preliminary studies of interactions, in a broad sense, between TB and several proteins of interest, are one of the necessary steps toward an increased understanding of TB's toxicity on mammalians.

Human serum albumin (HSA) is the most abundant plasma protein and contributes significantly to many transport and regulatory processes. It forms about $60 \%$ of the mass of human plasma proteins with a typical concentration of $40 \mathrm{mg} \cdot \mathrm{ml}^{-1}$ in the bloodstream $[24,10]$. The protein binds to a wide variety of substrates such as metals, fatty acids, amino acids, hormones and an impressive spectrum of drugs [19].

Recently, several studies have been carried out to examine the toxic effects of pesticides at the protein level $[23,4,32,30]$ but information about the possible impact of triazoles on plasma proteins is still limited [29, 34]. At the same time, a binding of pesticides including triazoles to plasma proteins has toxicological importance as it can significantly affect their distribution and excretion in the organism [25]. When these fungicides penetrate into the bloodstream, they may bind to plasma proteins and subsequently induce some alternations of the protein structure and function.

The aim of this study was to obtain additional information about the interactive properties of $\mathrm{TB}$ in relation to plasma proteins with regard to the above mentioned frequent application of $\mathrm{TB}$ as a pesticide. These results may provide basic data for clarifying the binding mechanisms of TB with HSA and be helpful for food security and human health when TB is applied as an antifungal agent. Fluorescence and far UV circular dichroism spectroscopy (far UV $\mathrm{CD}$ ) were used for a determination of the binding constant, mode of interaction between TB and human serum albumin molecules, and the effect of fungicide on the secondary structure of the HSA molecule.

\section{MATERIALS AND METHODS}

Tebuconazole (CAS Number 107534-96-3) was obtained from Sigma, and its grade was analytical standard. HSA (fatty acids free, globulin free, purity no less than 99\%) was purchased from Sigma and was used without further purification. To prepare stock solutions, TB was dissolved in $100 \%$ ethanol in a concentration of $10^{-3}$ mol. $1^{-1}$ and a stock solution of HSA (concentration $5 \times 10^{-4}$ mol. $\mathrm{l}^{-1}$ ) was prepared in Tris- $\mathrm{HCl}\left(0.05 \mathrm{~mol} . \mathrm{l}^{-1}\right.$ Tris $+0.1 \mathrm{~mol} . \mathrm{l}^{-1}$ $\mathrm{NaCl})$ buffer, pH 7.4. Phosphate buffer $\left(0.02 \mathrm{~mol}^{-1} \mathrm{l}^{-1}\right.$, $\mathrm{pH}$ 7.4) was used for the CD spectroscopic measurements. Tris(hydroxymethyl)aminomethane, $\mathrm{NaCl}, \mathrm{HCl}$, and other reagents were all of analytical purity.

Fluorescence measurements were performed using a spectrofluorometer SHIMADZU RF 5301 PC in $1 \mathrm{~cm}$ quartz cuvette. The excitation wavelength was $295 \mathrm{~nm}$ and fluorescence was collected at 300-500 nm emission wavelengths using $5 \mathrm{~nm} / 5 \mathrm{~nm}$ slits.

Complexes of TB/HSA for fluorescence spectroscopy were prepared by titration of TB into $2 \times 10^{-6} \mathrm{~mol} . \mathrm{l}^{-1} \mathrm{HSA}$ to have a final concentration of TB from $2 \times 10^{-6}$ mol. $\mathrm{l}^{-1}$ to $32 \times 10^{-6}$ mol. $1^{-1}$.

Far UV CD spectroscopy experiments were carried out by means of a CD spectrometer Jasco J-815 in $0.1 \mathrm{~cm}$ quartz cuvette at room temperature and constant nitrogen flush. The spectra of HSA in the presence of TB were recorded in the range $200-270 \mathrm{~nm}$ with a scan rate of $50 \mathrm{~nm} \cdot \mathrm{min}^{-1}$. 
Three scans were accumulated for each spectrum, taking the average as the final data.

Complexes of TB/HSA for CD spectroscopy were prepared by the titration of TB into $3.75 \times 10^{-6}$ mol. $1^{-1}$ HSA to obtain a final concentration of TB from $3.75 \times 10^{-6}$ mol. $1^{-1}$ $1.875 \times 10^{-5} \mathrm{~mol}^{-1} \mathrm{I}^{-1}$ The Tris- $\mathrm{HCl}$ buffer was replaced by phosphate buffer $\left(0.02 \mathrm{~mol}^{-1}, \mathrm{pH} 7.4\right)$ to eliminate the influence of $\mathrm{Cl}^{-}$ions. The helical content of free and bound HSA was calculated from the mean residue ellipticity (MRE) values at $209 \mathrm{~nm}$ using the following equation

$$
\% a-\text { helix }=\frac{-\mathrm{MRE}_{209 \mathrm{~nm}}-4000}{33000-4000} \times 100
$$

Graphical presentations were evaluated by software Origin, versions 6.0 and 8.0.

\section{RESULTS}

Fluorescence spectroscopy is an effective method to study the interactions between small molecules and bio macromolecules. Fluorescence quenching refers to any pro- cess, which decreases the fluorescence intensity of a sample. The fluorescence of fluorophores within the HSA macromolecule may change when HSA interacts with other molecules, which could be reflected in the fluorescence spectra of HSA in the UV region. The changes in emission intensity value, and wavelength of emission maximum, respectively, are evaluated at experimental processing. Whereas the fluorescence intensity is influenced by a change in the polarity of the microenvironment of bio macromolecule as well as movement of charged groups in the vicinity of the fluorophores inside, hydrophobic changes in the microenvironment primarily dictate the shift in the emission maximum [14]. The shift in the emission maximum is a good index to evaluate any alternation in the hydrophobicity of the binding region [8]. Our emission fluorescence spectra of HSA in the absence and presence of TB are shown in Figure 2. It can be seen that the fluorescence intensity of the HSA decreases as a result of the increasing concentration of TB. This result points to moderate fluorescence quenching effect (Fig. 2 inset) but at the same time a remarkable deformation of emission spectra can be seen (Fig. 2). It looks like there was a blue shift observed at the highest TB concentration used in this study, which should point to any

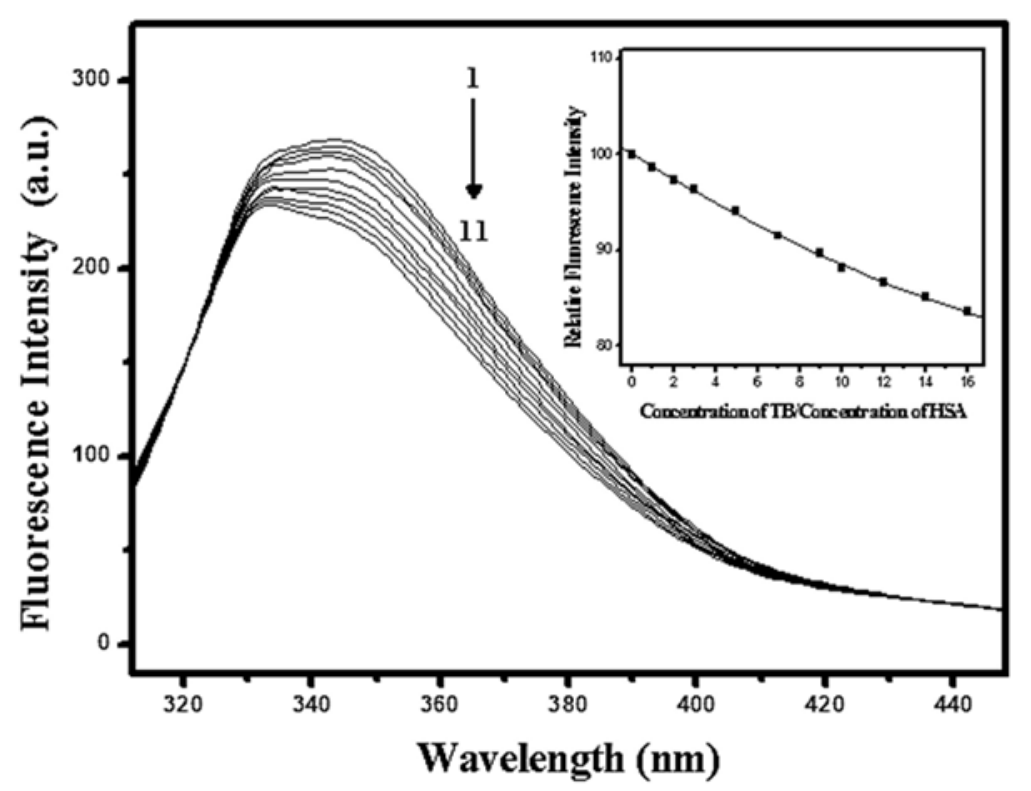

Fig. 2. Effect of tebuconazole on the fluorescence spectra of HSA

$\mathrm{c}(\mathrm{HSA})=2 \mu \mathrm{mol} . \mathrm{l}^{-1}$. Lines $1^{-1} 1: \mathrm{c}(\mathrm{TB})=0 ; 2.0 ; 4.0 ; 6.0 ; 10.0 ; 14.0 ; 18.0 ; 20.0 ; 24.0 ; 28.0 ; 32.0 \mu \mathrm{mol} . \mathrm{l}^{-1}$, respectively.

$\lambda_{\text {exc }}=295 \mathrm{~nm} ; \lambda_{\text {em }}=300-500 \mathrm{~nm} ; \mathrm{pH}=7.4 ; \mathrm{T}=298 \mathrm{~K}$

Inset: Fluorescence decrease of HSA upon TB binding at emission wavelength $344 \mathrm{~nm}$ 
alternation in the hydrophobicity of the binding region of the HSA. However, the deformation of the emission spectrum in Fig. 2 cannot be regarded as the blue shift in the emission maximum but it probably presents a sum of two individual fluorescence spectra with maximum at $332 \mathrm{~nm}$, and $351 \mathrm{~nm}$ respectively. Subsequently completed spectral deconvolution (not shown) has proven our above mentioned assumption. Considering a chemical structure of TB and hydrophobic cavity within the HSA macromolecule, two different modes of interaction between $\mathrm{TB}$ and the HSA can be assumed. At low concentration of TB, the TB molecules quench intrinsic fluorescence of HSA due to the interaction with the hydrophobic part of the protein showing a decrease in fluorescence intensity at $351 \mathrm{~nm}$. On the other hand, at higher concentrations of the TB in complex, some TB molecules are inert and they enable the HSA macromolecule to have unchanged emission spectrum at 332 $\mathrm{nm}$. Finally, we can assume there are two populations of the HSA macromolecules as a consequence of the interaction with $\mathrm{TB}$ at higher ratios.

A variety of molecular interactions can result in quenching, including excited-state reactions, molecular rearrangements, energy transfer, ground-state complex formation and collisional quenching [15]. The quenching mechanism can be described by the Stern-Volmer equation:

$$
\mathrm{F} 0 / \mathrm{F}=1+\mathrm{kq} \tau 0[\mathrm{Q}]=1+\mathrm{KSV}[\mathrm{Q}](1)
$$

Where F0 and F are the fluorescence intensities of the

a)

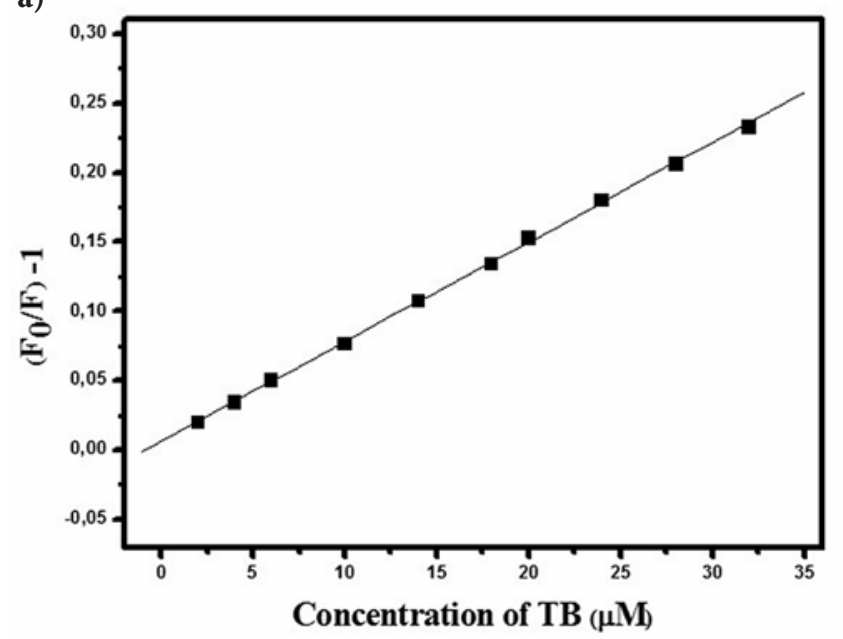

protein in the absence and presence of the quencher (TB), respectively. [Q] is the concentration of the quencher, $\mathrm{kq}$ is the bimolecular rate quenching constant, $\tau 0$ is the average lifetime of the biomolecule without quencher about $10 \mathrm{~ns}$ for most biomolecules [16] and KSV is the Stern-Volmer constant. The inverse value of KSV represents the quencher (TB) concentration at which $50 \%$ of the fluorophore intensity (HSA) is quenched.

The curve of (F0/F)-1 versus [Q] is shown in Fig. 3a. The corresponding kq and KSV constants for the TB/HSA complex were obtained by the fitting of the graphical representation of the Stern-Volmer equation. The quenching constants are summarized in Table 1.

\section{Identification of binding parameters}

If we assume static quenching then the association constant (KA) and the number of binding sites (n) in the bio macromolecule can be calculated by the following equation [31].

$$
\log (\mathrm{F} 0 / \mathrm{F}-1)=\log \mathrm{KA}+\mathrm{nlog}[\mathrm{Q}](2)
$$

Fitting the plot of $\log (\mathrm{F} 0 / \mathrm{F}-1)$ versus $\log [\mathrm{Q}]$ (so called Hill plot) for the interaction between the HSA and tebuconazole (Fig. 3b), the association constant and number of binding sites were obtained (Table 1).

To obtain more information on the binding of tebuconazole to HSA, circular dichroism spectroscopy was used to study the secondary structure of HSA and TB/HSA complex. $C D$ is a sensitive technique to monitor the conforma-

b)

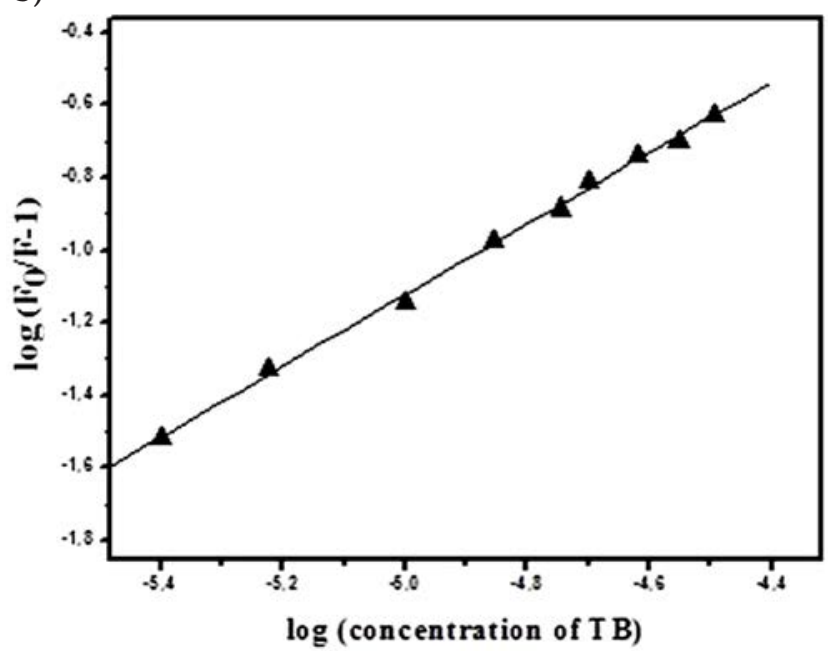

Fig. 3. a) Stern-Volmer representation of the fluorescence quenching of the HSA by tebuconazole; b) Hill plot for the determination of the binding parameters of the HSA interaction with TB $\mathrm{c}(\mathrm{HSA})=2 \mu \mathrm{mol.} \mathrm{1}^{-1} ; \lambda_{\text {exc }}=295 \mathrm{~nm} ; \lambda_{\mathrm{em}}=344 \mathrm{~nm}, \mathrm{pH}=7.4 ; \mathrm{T}=298 \mathrm{~K}$ 
Table 1. Bimolecular rate quenching constant (kq), Stern-Volmer quenching constant (KSV), association constant (KA) and number of binding sites $(\mathbf{n})$ at the physiological conditions

\begin{tabular}{ccccc}
\hline $\mathbf{T}(\mathbf{K})$ & $\begin{array}{c}\mathbf{k q} \\
{\left[\mathrm{l} . \mathrm{mol}^{-1} . \mathrm{s}^{-1}\right]}\end{array}$ & $\begin{array}{c}\mathbf{K S V} \\
{\left[\mathrm{l} . \mathrm{mol}^{-1}\right]}\end{array}$ & $\begin{array}{c}\text { KA } \\
{[\mathrm{l} . \mathrm{mol}}\end{array}$ & $\mathbf{n}$ \\
\hline 298 & $7.26 \times 10^{11}$ & $7.26 \times 10^{3}$ & $8.51 \times 10^{3}$ & 1.01 \\
\hline
\end{tabular}

tional changes in proteins. Far UV CD measurements were performed in the presence of TB at different concentrations but the CD spectra stayed identical for the final concentration ratio 5/1 (Fig. 4).

As can be seen from Fig. 4, the CD spectra of HSA and the complex, respectively, display two negative bands in the ultraviolet region at 209 and $223 \mathrm{~nm}$, characteristic of the a-helical structure of protein. The reasonable explanation is that the negative peak at $209 \mathrm{~nm}$ is contributed to $\pi \rightarrow \pi^{*}$ transition and $223 \mathrm{~nm}$ peak is contributed to $\mathrm{n} \rightarrow \pi^{*}$ transfer for the peptide bond of $\alpha$-helix [33].

As shown in Figure 4, TB alone (dotted line) does not show any optical activity in this region. The addition of TB to HSA leads to an increase in the CD signal without significant shift of the peaks indicating that the binding of TB to HSA induces an increase in the $\alpha$-helical content of HSA. The $\alpha$-helix content of HSA increased from $55 \%$ to $60 \%$ upon TB binding at a molar ratio of TB/HSA of $1 / 1$ and
$5 / 1$, implying that the TB binding results in a conformation change that stabilizes the HSA structure by increasing its $\alpha$-helical content. We assume that the increase of the a-helical content of HSA is realized at the expense of the random coil content when TB binds to the protein.

\section{DISCUSSION}

A better understanding of the interaction of the TB and other fungicides with various possible cellular targets is essential for the determination of their function in biological systems. The present contribution was focused on the results obtained in the study of TB associations with serum albumins represented by HSA.

The value of the association constant (Table 1) of the TB/HSA complex induced a slight binding affinity between the TB and the HSA. The interaction of four triazole fungicides (triadimefon, imazalil, myclobutanil, penconazole) with HSA has been reported in a comprehensive study by Zhang et al. [34]. The association constants determined by fluorescence quenching in this study range from $3.96 \times 10^{3} 1 . \mathrm{mol}^{-1}$ (triadimefon) to $8.47 \times 1031 . \mathrm{mol}^{-1}$ (penconazole) [34]. Our association constant for the TB/ HSA complex $\left(8.51 \times 1031 . \mathrm{mol}^{-1}\right)$ falls into this interval very well. The number of binding sites for TB, which is close to 1 (Table 1) corresponded with those obtained by Zhang

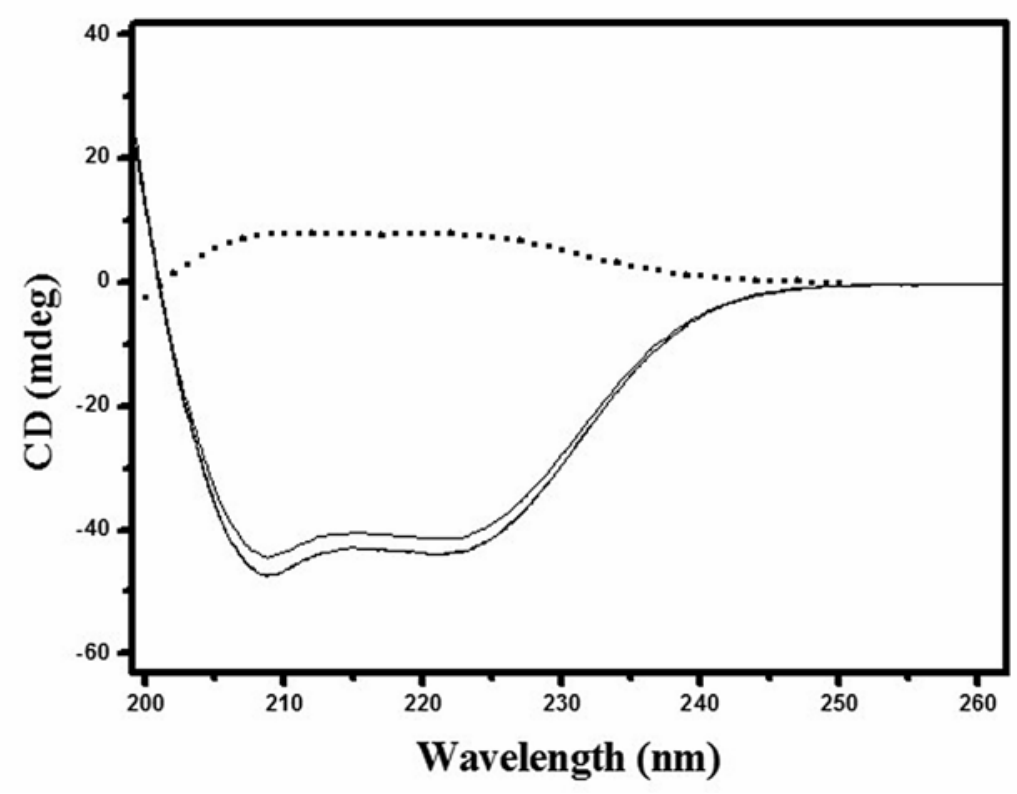

Fig. 4. Far UV CD spectra of HSA in absence and presence of TB

$\mathrm{c}(\mathrm{HSA})=3.75 \mu \mathrm{mol} . \mathrm{l}^{-1}, \mathrm{c}(\mathrm{TB})=0 ; 3.75 ; 18.75 \mu \mathrm{mol} . \mathrm{l}^{-1}$, phosphate buffer $\mathrm{pH}=7.4$ 
et al. [34]. Considering a chemical structure of all of the estimated triazole fungicides we may assume that both tebuconazole and penconazole molecules look similar. This fact can be one of many other reasons explaining their very similar binding affinity expressed by the association constants.

Comparing the binding affinities of other pesticides to HSA, we can consider the studies by Wang et al. [29] and Wang et al. [30]. They used the spectroscopic approach to find association constants for imidacloprid/HSA and thiacloprid/HSA. Both molecules represented the neonicotinoid insecticides currently being used in agriculture. Comparing the association constants of triazole and neonicotinoide pesticides we can declare that the binding affinity of triazole fungicides, including tebuconazole to HSA, is lower than those of neonicotinoides. But the differences are not very expressive.

It has previously been reported that the binding of certain ligands such as ciproflaxin [1], virstatin [13], phycocyanobilin [20] may cause a conformational change in HSA with an accompanying increase in its $\alpha$-helical content and protein structural stabilization. This phenomenon is quite striking for protein-ligand systems with high affinities, e.g., binding of biotin to streptavidin causes the disappearance of the band arising from unordered structure in FT-IR spectra [11]. Surprisingly, an increase in the TB concentration causes the CD signal of the HSA to be increased, which indicates an increase of the helical secondary structure content in the HSA macromolecule. On the contrary, with the above mentioned knowledge about the tendency to increase the helical content in high binding affinity ligands, the binding affinity of TB to HSA is only slight. But Wang et al. [29] have obtained the same result for a slightly bound imidacloprid to HSA. The increase in negative ellipticity as shown in Fig. 4 might be due to the shielding of the peptide strand in the HSA macromolecule due to the increase in hydrophobicity on binding with TB [28]. This conclusion agrees with the result of the fluorescence quenching experiment.

The present study investigated the interaction of the triazole fungicide tebuconazole with HSA by spectroscopic methods. TB can interact with HSA in vitro under simulated physiological conditions. Considering a static mechanism of fluorescence quenching of HSA by the TB, we have determined the association constant which expresses the binding affinity between both molecules. The value of this constant indicates a slight binding affinity in comparison to other ligands, but it corresponds with the binding parameters of other triazole fungicides very well. Furthermore, the interaction of TB led to slight conformational changes of the HSA macromolecule.

\section{ACKNOWLEDGEMENT}

This study was supported by the project VEGA 1/0176/16.

\section{REFERENCES}

1. Ahmad, B., Parveen, S., Khan, R.H., 2006: Effect of albumin conformation on the binding of ciprofloxacin to human serum albumin: a novel approach directly assigning binding sites. Biomacromolecules, 7, 1350-1356.

2. Bayer Cropscience Limited 2005: Environmental information sheet Folicur ${ }^{\circledast}$ MAPP number 11278. CPA Guidance Notes version 3. CEIS.

3. Clausen, C.A., Yang, W.V., 2007: Protecting wood from mould, decay, and termites with multicomponent biocide systems. Int. Biodeter. Biodegr., 59, 20-24.

4. Cui, Y., Guo, J.F., Xu, B.J., Chen, Z.Y., 2006: Binding of chlorpyrifos and cypermethrin to blood proteins. Pestic. Biochem. Phys., 85, 110.

5. Di Renzo, F., Broccia, M. L., Giavini, E., Menegola, E., 2007: Citral, an inhibitor of retinoic acid synthesis, attenuates the frequency and severity of branchial arch abnormalities induced by triazole-derivative fluconazole in rat embryos cultured in vitro. Reprod. Toxicol., 24, 326-332.

6. EFSA: Conclusion on the Peer Review of Tebuconazole 2008: EFSA Scientific Report, 176, 1-109.

7. Elsaesser, D., Schulz, R., 2008: Mitigation of fungicide pollution in vegetated agricultural surface waters: GIS modelling and monitoring in the field. In Conference Proceeding from the SETAC Europe 18th Annual Meeting, SETAC, Warsaw, 406-407.

8. Froehlich, E., Mandeville, J. S., Jenings, C. J., Sedaghat-Herati, R., Tajmir-Riahi, H. A., 2009: Dendrimers bind human serum albumin. J. Phys. Chem. B, 113, 6986-6993.

9. Fustinonu, S., Mercadante, R., Pollrdri, E., Rubino, F., Colosio, C., Moretto, A., 2012: Biomonitoring human exposure to tebuconazole. Toxicol. Lett., 211, S51.

10. Gelamo, E.L., Silva, C.H.T.P., Imasato, H., Tabak, M., 2004: On the hydrodynamics and temperature dependence 
of the solution conformation of human serum albumin from viscometry approach. Biochim. Biophys. Acta, 1700, 24.

11. Gonzáles, M., Bagatolli, L. A., Echabe, I., Arrondo, J.L.R., Argarana, C. E., Cantor, Ch. R., Fidelio, G. D., 1997: Interaction of biotin with streptavidin. J. Biol. Chem., 272, 1128811294.

12. Holečková, B., Dianovský, J., Šiviková, K., Mesarč, M., 2010: Detection of chromosomal aberrations in cattle cells after conazole fungicide treatment. Toxicol. Lett., 196S, S37-S351.

13. Chatterjee, T., Pal, A., Chatterjee, B.K., Chakrabarti, P., 2012: Interaction of virstatin with human serum albumin: spectroscopic analysis and molecular modelling. PloS ONE, 7, e37468

14. Khana, N.C., Tokuda, M., Waisman, D.M., 1986: Conformational changes induced by binding of divalent cations to calregulin. J. Biol. Chem., 261, 8883-8887.

15. Lakowicz, J. R., 1983: Quenching of Fluorescence. In Lakowicz, J.R.: Principles of Fluorescence Spectroscopy, Plenum Press: New York, NY, USA, 199-227.

16. Lakowicz, J. R., Weber, G., 1973: Quenching of fluorescence by oxygen: a probe for structural fluctuations in micro molecules. Biochemistry, 12, 4161-4170.

17. Liang, Y., Mengli, C. H., Yihua, L., Wenjun, G., Guonian, Z., 2013: Thyroid endocrine disruption in zebrafish larvae following exposure to hexaconazole and tebuconazole. Aquat. Toxicol., 138-139, 35-42.

18. Montuelle, B., Dorigo, A., Berard, B., Volat, A., Bouchez, A., Tlili, A., Gouy, V., Pesce, S., 2010: The periphyton as a multi metric bio indicator for assessing the impact of land use on rivers: an overview of the ArdiSres-Morcille experimental watershed (France). Hydrobiologia, 657, 123-141.

19. Peters, T. Jr., 1995: Ligand binding by albumin. In Peters, T. Jr.: All about Albumin. Academic Press, San Diego, 76-132.

20. Radibratovic, M., Minic, S., Stanic-Vucinic, D., Nikolic, M., Milcic, M., Cirkovic Velickovic, T., 2016: Stabilization of human serum albumin by the binding of phycocyanobili, a bioactive chromophore of blue-green alga spirulina: Molecular dynamics and experimental study. PloS ONE, 11, DOI:10.1371/journal.pone.0167973.

21. Robinson, J.F., Tonk, E. C. M., Verhoef, A., Piersma A.H., 2012: Triazole induced concentration-related gene signatures in rat whole embryo culture. Reprod. Toxicol., 34, 275-283.

22. Schummer, C., Salquébre, G., Briand, O., Millet, M., Appenzeller, B.M.R., 2012: Determination of farm workers' exposure to pesticides by hair analysis. Toxicol. Lett., 210, $203-210$.
23. Silva, D., Cortez, C. M., Bastos, J. C., 2004: Methyl parathion interaction with human and bovine serum albumin. Toxicol. Lett., 147, 53.

24. Sugio, S., Kashinma, A., Mochizuki, S., Noda, M., Kobayashi, K., 1999: Crystal structure of human serum albumin at 2.5 Å resolution. Protein Eng., 12, 439.

25. Sulkowska, A., Maciazek-Jurczik, M., Bojko, B., Rownicka, J., Zubik-Skupien, I., Temba, E., et al., 2008: Competitive binding of pheylbutazone and colchicines to serum albumin in multidrug therapy: a spectroscopic study. J. Mol. Struct., 881, 97.

26. Šiviková, K., Dianovský, J., Holečková, B., Galdíková, M., 2010: Effects of two selected fungicides on the frequency of SCI in bovine peripheral lymphocytes. Toxicol. Lett., 196S, S37-S351.

27. U. S. Environmental Protection Agency (U. S. EPA), 2006: Chemicals Evaluated for Carcinogenic Potential. Office of Pesticide Programs, U.S. Environmental Protection Agency, Washington, DC.

28. Varshney, A., Ansari, M., Zaidi, N., Ahmad, E., 2014: Analysis of binding interaction between antibacterial ciprofloxacin and human serum albumin by spectroscopic techniques. Cell Biochem. Biophys., DOI 10.1007/s12013-014-9863-1.

29. Wang, C., Li, Y., 2011: Study on the binding of propiconazole to protein by molecular modeling and a multi spectroscopic method. J. Agr. Food Chem., 59, 8507-8512.

30. Wang, Y., Tang, B., Zhang, H., Zhou, Q., Zhang, G., 2009: Studies on the interaction between imidacloprid and human serum albumin: Spectroscopic approach. J. Photoch. Photobio. B., 94, 183-190.

31. Xiang, G. H., Tong, C. L., Lin, H.Z., 2007: Nitroaniline isomers interaction with bovine serum albumin and toxicological implications. J. Fluoresc., 17, 22804-22809.

32. Yan, C. N., Mei, P., Guan, Z. J., Liu, Y., 2007: Studies on the thermodynamics features of the interaction between imidacloprid and bovine serum albumin. Chin. J. Chem., 25, 1085.

33. Yang, P., Gao, P., 2002: The Principle of Bioinorganic Chemistry, Science Press, Beijing, 322-342.

34. Zhang, J., Zhuang, S., Tong, C.H., Liu, W., 2013: Probing the molecular interaction of triazole fungicides with human serum albumin by multi spectroscopic techniques and molecular modeling. J. Agr. Food Chem., 61, 7203-7211.

Received March 29, 2018

Accepted May 18, 2018 